\title{
A Longitudinal Study of Physical Function in Patients with Early-Onset Dementia
}

\author{
Gro Gujord Tangen $^{\mathrm{a}}$ Elisabet Londos ${ }^{\mathrm{b}}$ Johan Olsson ${ }^{\mathrm{b}}$ \\ Lennart Minthon $^{\mathrm{b}} \quad$ Anne Marit Mengshoel ${ }^{\mathrm{a}}$ \\ ${ }^{a}$ Department of Health Sciences, University of Oslo, Oslo, Norway; ${ }^{b}$ Clinical Memory Research Unit, \\ Department of Clinical Sciences Malmö, Lund University, Lund, Sweden
}

\author{
Key Words \\ Dementia - Alzheimer's disease - Early onset - Mobility - Motor function • Physical \\ performance $\cdot$ Timed Up and Go Test
}

\begin{abstract}
Background: The aim of this study was to explore changes in mobility in terms of ambulation and transfer over 1 year in patients with early-onset Alzheimer's disease (EOAD), and to compare mobility in EOAD with patients with other types of early-onset dementia (EOOD). Method: Forty-two patients with EOAD and 30 patients with EOOD were included. All patients were homedwelling and had mild or moderate degree of dementia. Mobility was assessed using the Timed Up and Go Test (TUG), a modified version of the Clinical Outcome Variables Scale, timed stair walking, and timed rise from the floor. Results: The EOAD group performed significantly better than the EOOD group on all mobility tests. After 1 year, 25 persons with EOAD were tested again. The performance on TUG $(p=0.028)$ and stair walking $(p=0.02)$ had deteriorated at the 1-year follow-up in the EOAD group. Conclusion: Patients with EOAD performed better on mobility tasks than patients with EOOD, but their performance deteriorated at 1-year follow-up.
\end{abstract}

Copyright $\odot 2012$ S. Karger AG, Basel

\section{Introduction}

Early-onset dementia (EOD) is defined as onset of symptoms of dementia before the age of 65 years. Dementia may have a devastating effect on the life of patients regardless of age. However, persons under 65 years are likely to still be working, and they may be carers for both under-age children and elderly parents, so the disease affects both economy and fam- 
ily life in a different way than in older patients. EOD is less common than late-onset dementia (LOD) $[1,2]$, and time to correct diagnosis is often longer in patients with EOD than in those with LOD [3-5]. Alzheimer's disease (AD) is the most frequent diagnosis in both forms of dementia, but less dominant in EOD than in LOD [2, 6]. Differences in clinical presentation of early-onset $\mathrm{AD}$ (EOAD) and late-onset $\mathrm{AD}$ (LOAD), such as more apraxia and visuospatial impairment in EOAD, have been described [7, 8]. The clinical progression of the disease is traditionally thought to be faster in $\operatorname{EOAD}$ than in LOAD $[9,10]$; however, a recent study did not confirm these earlier findings [11]. Although cognitive impairment is the hallmark of dementia, physical function is important for the future prospects of patients with dementia. In LOAD, impaired physical function is associated with faster progression of the disease, higher risk of institutionalization, and higher mortality [12-14]. However, there are few studies dealing with physical function in patients with EOD.

In persons with EOAD we have found only one single study focusing on gait using welldescribed methods. Despite a small sample, the authors found that patients with mild EOAD walked more slowly than healthy controls, which suggests that physical function is affected to some extent even in persons with early-stage EOAD [15]. In other studies involving measures of physical function and EOD, physical function is examined as a factor in predicting mortality or to characterize EOD [16-19]. In a study of patients with EOAD, the presence of tremor and rigidity was the most significant predictor of mortality [17]. A Japanese study did not find an association between impaired motor function and mortality in patients with EOAD [19]. Another study found abnormal gait to be more common in LOAD than in EOAD [18]. Gait disturbances were only present in the final stages of EOAD in a kindred with an E280A presenilin-1 mutation [16]. The measures of physical function are poorly described in these latter studies. In patients with LOAD, reduced gait speed, balance and muscle strength, and increased prevalence of parkinsonian signs have been reported [20-24], but impairment of physical function in LOAD is still considered to be mild compared with other diagnoses in LOD [25]. These findings indicate that it is relevant to study physical function in EOD; however, studies using standardized methods and with a primary focus on physical function are still lacking.

Physical function is a broad term and in our study we have studied mobility defined as the ability to move from one place to another independently and safely [26]. Mobility is an important factor for living an independent life, and we believe the knowledge gained from the present study will be relevant to the daily lives of patients with EOD. Studying patients with EOD also gives us the opportunity to explore how dementia influences mobility in younger persons who are presumably less affected by age-related processes such as subcortical hyperintensities that may also influence mobility [27], and thereby could weaken the results in samples of patients with LOD. The aim of our study was twofold: firstly, we wanted to compare performance on measures of mobility in patients with EOAD and patients with other types of EOD. Secondly, we wanted to examine whether mobility changed over a 1-year observational period in patients with EOAD.

\section{Methods}

Participants

All 72 patients were recruited from the Memory Clinic Malmö (Sweden) in the period 2005-2011. The first 28 patients were consecutively included, most of them on their first visit to the clinic, while others had been attending the clinic for up to 2 years. Afterwards, another 44 patients were recruited from a prospective clinical observational study of EOD patients with a 3 -year follow-up. The inclusion criteria were the same for all patients: they 
had to be living at home and have mild or moderate EOD. Patients who needed assistance during the assessments of mobility were excluded.

\section{Diagnostics and Design}

All patients were given a comprehensive examination that included medical history, cognitive tests, neurological and psychiatric examination, laboratory tests, and computed tomography or magnetic resonance imaging of the brain. The clinical diagnosis of AD was based on the NINCDS-ADRDA criteria [28], vascular dementia (VaD) on the DSM-IV criteria, frontotemporal lobar degeneration (FTLD) on the Neary et al. [29] criteria, dementia with Lewy bodies (DLB) on the McKeith et al. [30] 2005 criteria, and other diagnoses on the DSM-IV criteria. Patients with diagnoses other than EOAD formed a heterogeneous group that we called early-onset other dementia (EOOD). This group consisted of patients with FTLD, VaD, mixed AD/VaD, DLB and Parkinson's disease with dementia, progressive supranuclear paresis, Creutzfeldt-Jakob disease, and unspecified dementia.

The internal board of ethics approved the study and all patients gave informed written consent to participating in the study.

\section{Patient Characteristics}

Demographic data, information on medication and evaluation of comorbidities and cognitive function were taken from medical journals or the records of the prospective study. Homozygote and heterozygote ApoE $\varepsilon 4$ alleles were considered together. Global cognitive status was evaluated by the Mini Mental State Examination (MMSE), scores ranging from 0 to 30 points, with higher scores indicating better performance [31].

\section{Assessment of Mobility}

Mobility assessments for all patients in the study were conducted by the same physical therapist (J.O.), who had long clinical experience of patients with dementia. The assessments were videotaped with a standardized video recording protocol for research purposes. Data on mobility performance were taken from the videotapes, and the timed assessments were recorded in seconds up to 1 decimal point by a physical therapist (G.G.T.) blinded for diagnoses at this point of the study.

Timed Up and Go Test. The Timed Up and Go Test (TUG) is widely used to assess basic functional mobility [32]. The patients were instructed to rise from a chair, walk at their normal pace to a line $3 \mathrm{~m}$ away, turn, walk back and sit down again. The patients were timed from the moment they moved their back away from the back of the chair until they were sitting down on the chair again. The physical therapist repeated the instructions if a patient displayed hesitation during performance. The need for cuing was noted as present or not present.

Timed Stair Walking. The patients were instructed to walk up a training staircase with handrails. They climbed three steps and walked over a level surface and down a sloping ramp on the other side. The patients were timed from the moment they placed one foot on the first step until both feet were back on the floor.

Timed Rising from the Floor. The patients lay supine on the floor on a soft training mat. They were instructed to get up and were timed from the moment they lifted their head from the floor until they were standing on both feet with the back erect.

Clinical Outcome Variables Scale (COVS) is an observational functional mobility scale for assessment of persons with neuromuscular and musculoskeletal disorders [33]. The original version consists of 13 items, each item scored on an ordinal scale from 1 to 7 . We chose to use only 5 of the 13 items: rolling to the side, supine lying to sitting over the bed edge, sitting balance, standing up from lying on the floor, and performance of ambulation. This 
modified version of COVS gave an overall score of 5 to 35 points, with higher scores indicating higher levels of independence.

\section{Statistical Analysis}

All analyses were performed using PASW Statistics 18.0 (SPSS Inc., Chicago, Ill., USA). Variables with normal distribution are presented with means and standard deviations, and variables with skewed distribution are presented with medians and interquartile ranges. Differences between the two diagnostic groups and gender, comorbidities, and cuing during TUG were analyzed using the $\chi^{2}$ test with Yates correction for continuity. Independent sample $t$ tests were used to compare continuous demographic variables between the EOAD and EOOD groups. Statistical significance for these analyses was set at $\mathrm{p}<0.05$.

Since there was a higher number of men in the EOOD group than in the EOAD group $(\mathrm{p}=0.110)$, we used univariate analysis of variance including gender as covariate to compare mobility scores in the EOAD and EOOD groups. Statistical significance was set at $\mathrm{p}<0.01$ for the univariate analysis due to violation of the homogeneity of variance assumptions. Multiple linear regression was used to determine the variables that were associated with the time on TUG as the dependent variable. Bivariate correlation analyses were performed to determine which independent variables we should include in the model and to ensure that these were not highly correlated with each other. Diagnostic group, education, MMSE, and gender were chosen as they were associated with TUG at $\mathrm{p}<0.2$. In addition, we included comorbidity based on clinical reasoning. Multiple regression was carried out using the backward removal strategy, excluding the variable with the highest $p$ value in each step.

The paired samples $t$ test and McNemar's test were used to compare the results between baseline and 1-year follow-up in the EOAD group, with $\mathrm{p}<0.05$ as the level of significance.

\section{Results}

All patients agreed to participate and only 1 patient, with $\mathrm{VaD}$, was excluded because he needed assistance during the mobility assessments. None of the patients used a walking device. To verify whether we had a biased selection as a result of the two different recruitment procedures, we compared the groups and found no differences with regard to MMSE ( $\mathrm{p}=$ $0.40)$, age $(\mathrm{p}=0.91)$, gender $(\mathrm{p}=0.11)$ or proportion of $\mathrm{AD}(\mathrm{p}=0.57)$ between the first 28 patients and the 44 patients from the prospective study.

In the longitudinal part of the study, 13 of the patients with $\mathrm{AD}$ had dropped out from the study: 4 had moved into a nursing home, 1 had moved from Malmö, and 3 declined further participation. Five of the patients had not yet reached 12 months after baseline at the time we closed the assessments. The patients with EOAD who only participated in the crosssectional part of the study had a higher mean age than those who also attended the 1-year follow-up $(61.8 \pm 3.5$ vs. $59.7 \pm 3.9$ years); however, this was not statistically significant. Neither were there any differences in MMSE score $(p=0.57)$, TUG $(p=0.29)$, gender $(p=$ 0.51 ) or years of education ( $\mathrm{p}=0.13$ ). In the EOOD group, only 11 patients attended the follow-up, so this sample is too small for statistical analysis.

\section{Baseline Comparisons between the EOAD and the EOOD Group}

Demographic and clinical characteristics of the patients in both groups are presented in table 1 . The only differences between the EOAD and EOOD groups were that there were more neurological disorders in the EOOD group $(\mathrm{p}=0.001)$ and more patients using cholinesterase inhibitors in the EOAD group $(\mathrm{p}=0.004)$. The patients with EOOD performed less 
Table 1. Demographic and clinical characteristics of the EOAD and the EOOD group

\begin{tabular}{lccc}
\hline & EOAD $(\mathrm{n}=42)$ & $\mathrm{EOOD}(\mathrm{n}=30)$ & $\mathrm{p}$ \\
\hline Men & $16(38.1)$ & $18(60)$ & 0.110 \\
Age, years & $60.6 \pm 3.8$ & $61.4 \pm 4.4$ & 0.377 \\
MMSE $^{1}$ & $21.3 \pm 5.4$ & $20.4 \pm 4.5$ & 0.485 \\
Education, years $^{2}$ & $10.7 \pm 2.3$ & $10.8 \pm 2.6$ & 0.771 \\
Employment status $^{3}$ & & & \\
$\quad$ Working & $7(18.4)$ & $8(30.8)$ & 0.398 \\
$\quad$ Sick leave/disability pension & $18(47.4)$ & $10(38.5)$ & 0.653 \\
$\quad$ Retired & $9(23.7)$ & $5(19.2)$ & 1.0 \\
$\quad$ Other & $4(10.5)$ & $3(11.5)$ & 1.0 \\
Cholinesterase inhibitors & $31(73.8)$ & $11(36.7)$ & 0.004 \\
Memantine & $6(14.3)$ & $10(33.3)$ & 0.103 \\
Medical conditions & $10(23.8)$ & $7(23.3)$ & 1.0 \\
$\quad$ Musculoskeletal & 0 & $8(26.7)$ & $<0.001$ \\
$\quad$ Neurological & $9(21.4)$ & $11(36.7)$ & 0.248 \\
$\quad$ Cardiovascular & $25(67.6)$ & $14(50)$ & 0.24 \\
ApoE 84 carrier & & &
\end{tabular}

Values are means \pm SD or numbers with percentages in parentheses. Missing data, EOAD/EOOD: ${ }^{1} 7 / 5 ;{ }^{2} 2 / 6 ;{ }^{3} 4 / 4 ;{ }^{4} 5 / 2$.

Table 2. Comparison of performance-based measures of mobility between patients with EOAD and patients with EOOD, adjusted for gender

\begin{tabular}{|c|c|c|c|c|}
\hline & Total & $\begin{array}{l}\text { EOAD } \\
(\mathrm{n}=42)\end{array}$ & $\begin{array}{l}\text { EOOD } \\
(\mathrm{n}=30)\end{array}$ & $\mathrm{p}$ \\
\hline Mean TUG $\pm S D, s$ & $11.9 \pm 4.2$ & $10.6 \pm 3.0$ & $13.7 \pm 4.8$ & 0.003 \\
\hline Cuing during TUG, \% & 34.3 & 36.6 & 31 & 0.821 \\
\hline Median timed stair walking (IQR), s & $4.4(2.8)$ & $4.3(1.8)$ & $6.6(5.2)$ & $<0.001$ \\
\hline Median rising from the floor (IQR), s & $6.6(5.3)$ & $5.5(3.2)$ & $9.7(10.0)$ & $<0.001$ \\
\hline Median modified COVS ${ }^{1}(\mathrm{IQR})$, points & $34.0(4.0)$ & $34.0(1)$ & $32.0(5)$ & $<0.001$ \\
\hline
\end{tabular}

IQR $=$ Interquartile range. ${ }^{1}$ The COVS has $0-35$ points, higher scores indicating better performance.

well than the patients with EOAD on all measures of mobility at baseline, as shown in table 2 . In the multivariable model, only the diagnostic group was significantly associated with TUG (adjusted $\beta=3.7,95 \% \mathrm{CI}-5.7$ to $-1.8 ; \mathrm{p}<0.01$ ), indicating that having a diagnosis other than AD increased the time on TUG by $3.7 \mathrm{~s}$. Adjusted $\mathrm{R}^{2}$ was 0.23 .

\section{Longitudinal Results in the EOAD Group}

At 1-year follow-up, the patients with EOAD performed less well on TUG $(\mathrm{p}=0.028)$ and timed stair walking $(\mathrm{p}=0.02)$ than they had done 1 year previously (table 3 ). There was no difference in the need for cuing during TUG between baseline and follow-up ( $\mathrm{p}=1.0)$. Figure 1 shows that few of the patients had improved results on TUG at 1-year follow-up. 
Table 3. One-year change in mobility in 25 patients with EOAD

\begin{tabular}{lclrl}
\hline & Baseline & 1-year follow-up & Difference & $\mathrm{p}$ \\
\hline Mean TUG \pm SD, s & $10.2 \pm 2.5$ & $11.1 \pm 2.9$ & $0.91 \pm 2.0$ & 0.028 \\
Cuing during TUG, \% & 40 & 36 & & 1.0 \\
Mean timed stair walking \pm SD, s & $4.7 \pm 1.6$ & $5.3 \pm 2.3$ & $0.64 \pm 1.3$ & 0.020 \\
Mean rising from the floor \pm SD, s & $5.8 \pm 1.9$ & $6.1 \pm 2.1$ & $0.25 \pm 2.0$ & 0.561 \\
Median modified COVS ${ }^{1}(\mathrm{IQR})$, points & $35.0(1)$ & $35.0(2)$ & $-0.21 \pm 1.3$ & 0.447
\end{tabular}

$\mathrm{IQR}=$ Interquartile range. ${ }^{1}$ The COVS has $0-35$ points, higher scores indicating better performance.

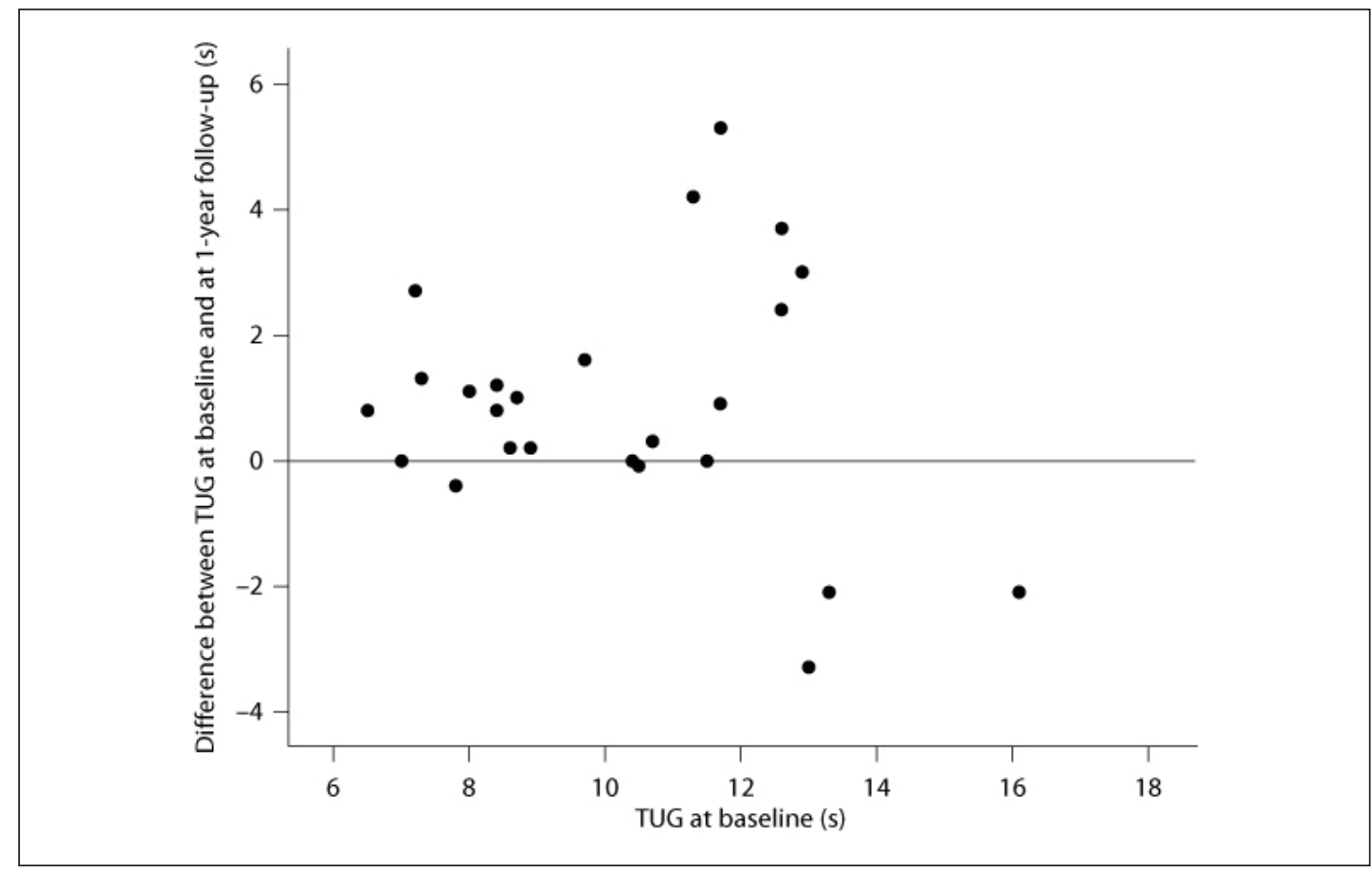

Fig. 1. Differences in seconds on the TUG between baseline and 1-year follow-up plotted against the time at baseline in 25 patients with EOAD. The horizontal line indicates no difference between the two time points.

\section{Discussion}

In the cross-sectional part of the study, we found that patients with EOAD performed better on measures of mobility than patients with EOOD. In the longitudinal part, the patients with EOAD performed less well on timed measures of mobility than they did 1 year previously.

To our knowledge, this is the first study comparing mobility in patients with EOAD with other EOD patients. Our results are in line with the comprehensive study by Allan et al. [25] who found that patients with LOAD performed better on balance and gait tests than patients with VaD, Parkinson's disease with dementia, and DLB. Pettersson et al. [22] also found that patients with other dementias performed less well than patients with $\mathrm{AD}$ (they did not divide 
between EOAD and LOAD in their analyses) on performance-based measures of mobility. On the other hand, Merory et al. [34] found no differences in gait pattern in terms of velocity, cadence or stride length between patients with LOAD and those with DLB, although the DLB patients were younger and had a higher MMSE score. One explanation for the difference in mobility between patients with EOAD and EOOD is probably the presence of underlying neurological diseases such as minor stroke and Parkinson's disease, which were naturally more frequent in the EOOD group.

The second finding in our study was that patients with EOAD were slower on TUG and timed stair walking 1 year after baseline. We had expected these younger patients with dementia to have a better reserve capacity than patients with LOAD, and that 1 year might be too short a period to detect changes in mobility. It should also be noted that patients with mixed $\mathrm{AD} / \mathrm{VaD}$ were not included in our EOAD group. There are no other longitudinal studies on patients with EOAD with which to compare our findings. However, Wittwer et al. [35] found decreased gait velocity in patients with LOAD during 1-year follow-up. Hebert et al. [36] reported a decrease in composite score for walking, turning, and repeated chair stands in patients with LOAD in a study with 4-year follow-up. The patients who dropped out of our study did not differ from those who attended the 1-year follow-up, apart from a tendency to be older. We do notice that 4 patients had dropped out because they had entered a nursing home. This could be due to a functional decline, and we believe that the change in mobility scores could be even larger if these patients had remained in the study. Our findings strengthen similar findings in patients with LOAD. The fact that even younger patients with EOAD suffer from deterioration in mobility makes it less likely that changes in mobility are related to ageing processes, but more likely that they are related to processes of dementia.

Persons with dementia often have difficulty understanding and carrying out instructions. While the rising from the floor, stair climbing, and COVS tasks have short instructions with only one element (e.g. 'rise up'), the apparently simple instructions in TUG contain more than one element, and if a patient forgets part of the instruction, this will influence the time to completion. Previous studies have also noted that patients with AD need cuing during TUG [37]. In our sample, the number of patients who needed cuing was unchanged from baseline to follow-up, which means that the slower performance at follow-up in our study cannot be explained by a greater need for cuing due to deterioration in cognitive function. Nor was there any difference in the need for cuing between the EOAD and EOOD groups in the cross-sectional part of the study. Apart from cuing during TUG, we did not examine causal explanations for the changes in mobility in the EOAD group in this study. We believe that the changes can be explained by a number of different factors, ranging from neuropathology to behavioral changes such as uncertainty in moving and physical inactivity.

In our study, both the EOAD group and the EOOD group were slower than the suggested reference values for TUG, where the mean reference value is 8.1 (95\% CI 7.1-9.0) s for the age group 60-69 years and 9.2 (95\% CI 8.2-10.2) s for the age group 70-79 years [38]. The mean change over 1 year in our EOAD group was $0.9 \mathrm{~s}$; this is close to the change over 10 years in the reference values. Thus, even the small deterioration we observed could be clinically relevant. Corresponding Swedish reference values for TUG were recently published for cognitively well-functioning persons aged 60-69 years [39]. In this population, mean time on TUG was $8.8 \pm 1.67 \mathrm{~s}$, which is well below both our patient groups. The gap between the TUG reference values and the performance of our patients is in line with the study that found that patients with EOAD walked slower than the healthy control group [15]. The changes we observed over 1 year may not influence daily life, but the trend towards deterioration in mobility in these relatively young patients is still of clinical concern. 
A strength of our study is that the Memory Clinic is responsible for making the diagnosis of all persons younger than 65 years with dementia in Malmö apart from persons with suspected FTLD. We therefore believe our EOAD group is representative of ambulatory, home-dwelling persons with EOAD in the general population. Our EOOD group had a low proportion of FTLD compared with other studies from Memory Clinics with EOD patients $[1,40,41]$. A study of patients with FTLD and AD found that patients with AD walked more slowly than those with FTLD [42], so we may have overestimated the difference in mobility between the EOAD and EOOD groups. Our findings are, however, in line with studies where mobility performance was compared in LOAD and other patients with dementia (not including FTLD) $[22,25]$. An additional limitation is that some demographic data and MMSE scores were lacking for the first 28 patients. However, the data on mobility testing were complete, and all patients were in a mild or moderate stage of dementia. The modified version of COVS had a ceiling effect in our patients with EOAD and any changes over 1 year may have been overlooked with this measure. Lastly, our sample was small, which makes the study vulnerable to type II errors. However, the difference between the EOAD and EOOD groups was significant, and we also found consistent significant changes on TUG and stair walking in the EOAD group over 1 year.

In conclusion, this sample of patients with mild to moderate EOAD experienced deterioration in mobility from baseline to 1-year follow-up. Patients with EOOD performed less well on the mobility tests than patients with EOAD at baseline. Our findings are in line with the results of studies involving patients with LOD, and may be clinically relevant for patients with dementia. We suggest that future studies of physical function in EOD should include more patients with other dementias so that the most common diagnoses can be analyzed separately.

\section{Acknowledgments}

The authors thank all the patients for their cooperation in this study. They also thank the Swedish Research Council (No. 523-2010-520) and the governmental funding of clinical research within the national health services (ALF) which supported this study.

\section{Disclosure Statement}

The authors declare no conflicts of interest.

\section{References}

-1 Papageorgiou SG, Kontaxis T, Bonakis A, Kalfakis N, Vassilopoulos D: Frequency and causes of early-onset dementia in a tertiary referral center in Athens. Alzheimer Dis Assoc Disord 2009;23:347351.

-2 Picard C, Pasquier F, Martinaud O, Hannequin D, Godefroy O: Early onset dementia: characteristics in a large cohort from academic memory clinics. Alzheimer Dis Assoc Disord 2011;25:203-205.

-3 Ron MA, Toone BK, Garralda ME, Lishman WA: Diagnostic accuracy in presenile dementia. Br J Psychiatry 1979;134:161-168.

4 Nott PN, Fleminger JJ: Presenile dementia: the difficulties of early diagnosis. Acta Psychiatr Scand 1975;51:210-217.

-5 Luscombe G, Brodaty H, Freeth S: Younger people with dementia: diagnostic issues, effects on carers and use of services. Int J Geriatr Psychiatry 1998;13:323-330. 
-6 Harvey RJ, Skelton-Robinson M, Rossor MN: The prevalence and causes of dementia in people under the age of 65 years. J Neurol Neurosurg Psychiatry 2003;74:1206-1209.

-7 Balasa M, Gelpi E, Antonell A, Rey MJ, Sanchez-Valle R, Molinuevo JL, Llado A: Clinical features and APOE genotype of pathologically proven early-onset Alzheimer disease. Neurology 2011;76: $1720-1725$.

-8 Koedam EL, Lauffer V, van der Vlies AE, van der Flier WM, Scheltens P, Pijnenburg YA: Early- versus late-onset Alzheimer's disease: more than age alone. J Alzheimers Dis 2010;19:1401-1408.

-9 Lucca U, Comelli M, Tettamanti M, Tiraboschi P, Spagnoli A: Rate of progression and prognostic factors in Alzheimer's disease: a prospective study. J Am Geriatr Soc 1993;41:45-49.

-10 Ho GJ, Hansen LA, Alford MF, Foster K, Salmon DP, Galasko D, Thal LJ, Masliah E: Age at onset is associated with disease severity in Lewy body variant and Alzheimer's disease. Neuroreport 2002;13: $1825-1828$.

-11 Gronning H, Rahmani A, Gyllenborg J, Dessau RB, Hogh P: Does Alzheimer's disease with early onset progress faster than with late onset? A case-control study of clinical progression and cerebrospinal fluid biomarkers. Dement Geriatr Cogn Disord 2012;33:111-117.

-12 Lopez OL, Wisnieski SR, Becker JT, Boller F, DeKosky ST: Extrapyramidal signs in patients with probable Alzheimer disease. Arch Neurol 1997;54:969-975.

-13 Scarmeas N, Albert M, Brandt J, Blacker D, Hadjigeorgiou G, Papadimitriou A, Dubois B, Sarazin M, Wegesin D, Marder K, Bell K, Honig L, Stern Y: Motor signs predict poor outcomes in Alzheimer disease. Neurology 2005;64:1696-1703.

-14 Wilson RS, Bennett DA, Gilley DW, Beckett LA, Schneider JA, Evans DA: Progression of parkinsonism and loss of cognitive function in Alzheimer disease. Arch Neurol 2000;57:855-860.

-15 Pettersson AF, Olsson E, Wahlund LO: Effect of divided attention on gait in subjects with and without cognitive impairment. J Geriatr Psychiatry Neurol 2007;20:58-62.

-16 Lopera F, Ardilla A, Martinez A, Madrigal L, Arango-Viana JC, Lemere CA, Arango-Lasprilla JC, Hincapie L, Arcos-Burgos M, Ossa JE, Behrens IM, Norton J, Lendon C, Goate AM, Ruiz-Linares A, Rosselli M, Kosik KS: Clinical features of early-onset Alzheimer disease in a large kindred with an E280A presenilin-1 mutation. JAMA 1997;277:793-799.

-17 Samson WN, van Duijn CM, Hop WC, Hofman A: Clinical features and mortality in patients with early-onset Alzheimer's disease. Eur Neurol 1996;36:103-106.

-18 Seltzer B, Sherwin I: A comparison of clinical features in early- and late-onset primary degenerative dementia. One entity or two? Arch Neurol 1983;40:143-146.

19 Ueki A, Shinjo H, Shimode H, Nakajima T, Morita Y: Factors associated with mortality in patients with early-onset Alzheimer's disease: a five-year longitudinal study. Int J Geriatr Psychiatry 2001;16: $810-815$.

-20 Eggermont LH, Gavett BE, Volkers KM, Blankevoort CG, Scherder EJ, Jefferson AL, Steinberg E, Nair A, Green RC, Stern RA: Lower-extremity function in cognitively healthy aging, mild cognitive impairment, and Alzheimer's disease. Arch Phys Med Rehabil 2010;91:584-588.

-21 Pettersson AF, Engardt M, Wahlund LO: Activity level and balance in subjects with mild Alzheimer's disease. Dement Geriatr Cogn Disord 2002;13:213-216.

-22 Pettersson AF, Olsson E, Wahlund LO: Motor function in subjects with mild cognitive impairment and early Alzheimer's disease. Dement Geriatr Cogn Disord 2005;19:299-304.

-23 Mazoteras Muñoz V, Abellan van Kan G, Cantet C, Cortes F, Ousset PJ, Rolland Y, Vellas B: Gait and balance impairments in Alzheimer disease patients. Alzheimer Dis Assoc Disord 2010;24:79-84.

-24 Bramell-Risberg E, Jarnlo GB, Minthon L, Elmstahl S: Lower gait speed in older women with dementia compared with controls. Dement Geriatr Cogn Disord 2005;20:298-305.

-25 Allan LM, Ballard CG, Burn DJ, Kenny RA: Prevalence and severity of gait disorders in Alzheimer's and non-Alzheimer's dementias. J Am Geriatr Soc 2005;53:1681-1687.

26 Shumway-Cook A, Woollacott M: Motor Control. Translating Research into Clinical Practice, ed 3. Philadelphia, Lippincott Williams \& Wilkins, 2007.

-27 Nadkarni NK, McIlroy WE, Mawji E, Black SE: Gait and subcortical hyperintensities in mild Alzheimer's disease and aging. Dement Geriatr Cogn Disord 2009;28:295-301.

-28 McKhann G, Drachman D, Folstein M, Katzman R, Price D, Stadlan EM: Clinical diagnosis of Alzheimer's disease: report of the NINCDS-ADRDA Work Group under the auspices of Department of Health and Human Services Task Force on Alzheimer's Disease. Neurology 1984;34:939-944. 
-29 Neary D, Snowden JS, Gustafson L, Passant U, Stuss D, Black S, Freedman M, Kertesz A, Robert PH, Albert M, Boone K, Miller BL, Cummings J, Benson DF: Frontotemporal lobar degeneration: a consensus on clinical diagnostic criteria. Neurology 1998;51:1546-1554.

-30 McKeith IG, Dickson DW, Lowe J, Emre M, O’Brien JT, Feldman H, Cummings J, Duda JE, Lippa C, Perry EK, Aarsland D, Arai H, Ballard CG, Boeve B, Burn DJ, Costa D, Del ST, Dubois B, Galasko D, Gauthier S, Goetz CG, Gomez-Tortosa E, Halliday G, Hansen LA, Hardy J, Iwatsubo T, Kalaria RN, Kaufer D, Kenny RA, Korczyn A, Kosaka K, Lee VM, Lees A, Litvan I, Londos E, Lopez OL, Minoshima S, Mizuno Y, Molina JA, Mukaetova-Ladinska EB, Pasquier F, Perry RH, Schulz JB, Trojanowski JQ, Yamada M: Diagnosis and management of dementia with Lewy bodies: third report of the DLB Consortium. Neurology 2005;65:1863-1872.

-31 Folstein MF, Folstein SE, McHugh PR: 'Mini-Mental State'. A practical method for grading the cognitive state of patients for the clinician. J Psychiatr Res 1975;12:189-198.

-32 Podsiadlo D, Richardson S: The timed 'Up \& Go': a test of basic functional mobility for frail elderly persons. J Am Geriatr Soc 1991;39:142-148.

33 Seaby L, Torrance G: Reliability of a physiotherapy functional assessment used in a rehabilitation setting. Physiother Can 1989;41:264-271.

-34 Merory JR, Wittwer JE, Rowe CC, Webster KE: Quantitative gait analysis in patients with dementia with Lewy bodies and Alzheimer's disease. Gait Posture 2007;26:414-419.

-35 Wittwer JE, Webster KE, Menz HB: A longitudinal study of measures of walking in people with Alzheimer's disease. Gait Posture 2010;32:113-117.

-36 Hebert LE, Scherr PA, McCann JJ, Bienias JL, Evans DA: Change in direct measures of physical performance among persons with Alzheimer's disease. Aging Ment Health 2008;12:729-734.

-37 Nordin E, Rosendahl E, Lundin-Olsson L: Timed 'Up \& Go' test: reliability in older people dependent in activities of daily living - focus on cognitive state. Phys Ther 2006;86:646-655.

-38 Bohannon RW: Reference values for the timed up and go test: a descriptive meta-analysis. J Geriatr Phys Ther 2006;29:64-68.

-39 Bramell-Risberg E, Jarnlo GB, Elmstahl S: Separate physical tests of lower extremities and postural control are associated with cognitive impairment. Results from the general population study Good Aging in Skane (GAS-SNAC). Clin Interv Aging 2012;7:195-205.

-40 Garre-Olmo J, Genis BD, del Mar FM, Marquez DF, de Eugenio HR, Casadevall T, Turbau RJ, Turon EA, Lopez-Pousa S: Incidence and subtypes of early-onset dementia in a geographically defined general population. Neurology 2010;75:1249-1255.

-41 Shinagawa S, Ikeda M, Toyota Y, Matsumoto T, Matsumoto N, Mori T, Ishikawa T, Fukuhara R, Komori K, Hokoishi K, Tanabe H: Frequency and clinical characteristics of early-onset dementia in consecutive patients in a memory clinic. Dement Geriatr Cogn Disord 2007;24:42-47.

-42 Allali G, Dubois B, Assal F, Lallart E, de Souza LC, Bertoux M, Annweiler C, Herrmann FR, Levy R, Beauchet O: Frontotemporal dementia: pathology of gait? Mov Disord 2010;25:731-737. 